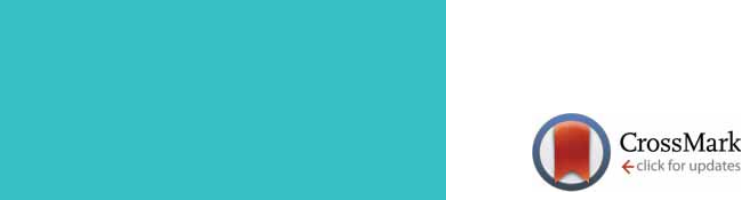

\title{
Bulbar impairment score and survival of stable amyotrophic lateral sclerosis patients after noninvasive ventilation initiation
}

\author{
Jesús Sancho ${ }^{1,2}$, Daniel Martínez ${ }^{3}$, Enric Bures ${ }^{1,2}$, José Luis Díaz ${ }^{1,2,4}$, \\ Alejandro Ponz ${ }^{5}$ and Emilio Servera ${ }^{1,2,6}$
}

\begin{abstract}
Affiliations: ${ }^{1}$ Respiratory Care Unit, Respiratory Medicine Dept, Hospital Clínico Universitario, Valencia, Spain. ${ }^{2}$ Research Group for Respiratory Problems in Neuromuscular Disease, Institute of Health Research INCLIVA, Valencia, Spain. ${ }^{3}$ Respiratory Medicine Section, Hospital Marina Baixa, Villajoyosa, Spain. ${ }^{4}$ Gasmedi SLU, Grupo Air Liquide, Madrid, Spain. ${ }^{5}$ Neurology Dept, Hospital Clínico Universitario, Valencia, Spain. ${ }^{6}$ Universitat de Valencia, Valencia, Spain.
\end{abstract}

Correspondence: Jesús Sancho, Respiratory Care Unit, Respiratory Medicine Dept, Hospital Clínico Universitario, Avd Blasco Ibañez 17, 46010 Valencia, Spain. E-mail: jesus.sanchođuv.es

ABSTRACT There is general agreement that noninvasive ventilation (NIV) prolongs survival in amyotrophic lateral sclerosis (ALS) and that the main cause of NIV failure is the severity of bulbar dysfunction. However, there is no evidence that bulbar impairment is a contraindication for NIV. The aim of this study was to determine the effect of bulbar impairment on survival in ALS patients with NIV.

ALS patients for whom NIV was indicated were included. Those patients who refused NIV were taken as the control group.

120 patients who underwent NIV and 20 who refused NIV were included. The NIV group presented longer survival (median 18.50 months, 95\% CI 12.62-24.38 months) than the no-NIV group (3.00 months, 95\% CI $0.82-5.18$ months $)(\mathrm{p}<0.001)$ and also in those patients with severe bulbar dysfunction (13.00 months (95\% CI 9.49-16.50 months) versus 3.00 months (95\% CI $0.85-5.15$ months), $\mathrm{p}<0.001$ ). Prognostic factors for ALS using NIV, adjusted for NIV failure, were severity of bulbar dysfunction (hazard ratio (HR) $0.5,95 \%$ CI $0.92-0.97 ; \mathrm{p}=0.001$ ) and time spent with oxygen saturation measured by pulse oximetry $<90 \%$ (\%sleep $\left.\mathrm{PpO}_{2}<90\right)$ using NIV (HR 1.12, 95\% CI 1.01-1.24; $\mathrm{p}=0.02$ ).

Severe bulbar impairment in ALS does not always prevent NIV from being used, but the severity of bulbar dysfunction at NIV initiation and $\%$ sleep $\mathrm{PO}_{2}<90$ while using NIV appear to be the main prognostic factors of NIV failure in ALS.

@ERSpublications

NIV prolongs survival in some ALS patients with severe bulbar impairment at NIV indication http://ow.ly/vFr530iCwnj

Cite this article as: Sancho J, Martínez D, Bures E, et al. Bulbar impairment score and survival of stable amyotrophic lateral sclerosis patients after noninvasive ventilation initiation. ERJ Open Res 2018; 4: 00159-2017 [https://doi.org/10.1183/23120541.00159-2017].

Received: Dec 122017 | Accepted after revision: Feb 092018

Copyright $\odot$ ERS 2018. This article is open access and distributed under the terms of the Creative Commons Attribution Non-Commercial Licence 4.0. 


\section{Introduction}

Noninvasive ventilation (NIV) has demonstrated its usefulness in extending survival, relieving symptoms, improving quality of life and avoiding the hospitalisation of patients with amyotrophic lateral sclerosis (ALS) $[1,2]$. As early-stage ventilatory disturbances occur at night, NIV in ALS patients is first used during sleep but as the disease progresses and the respiratory muscles become weaker, daytime NIV may become necessary to support life $[1,3]$. Continuous NIV has proven to be able to prolong survival in some neuromuscular diseases with no (or little) bulbar impairment when respiratory muscles are unable to maintain adequate alveolar ventilation, even if only for short periods of time [4]; however, in clinical practice, continuous NIV can delay initiation of ventilatory support via tracheostomy or palliative care for only a minority of ALS patients [5]. It has been consistently argued that bulbar impairment, rather than respiratory muscle weakness, is the key factor in the ineffectiveness of continuous NIV in ALS [3].

Regardless of whether the onset of ALS is bulbar or spinal, the majority of patients will develop bulbar dysfunction as the disease progresses, and most also develop severe bulbar dysfunction before becoming dependent on continuous NIV [6]. There is evidence that bulbar impairment is associated with poor tolerance and lesser effectiveness of NIV in ALS, both with volume and pressure NIV [7], but there is insufficient information regarding the ability of NIV to prolong survival in those ALS patients with severe bulbar dysfunction at NIV initiation [2]. This gap in knowledge is an important obstacle for shared decision-making with patients and for planning medium and long-term treatment.

There has been little research regarding prognostic factors in ALS patients on long-term NIV. The current knowledge exposes that adequate and effective NIV and respiratory secretion management is essential to counteract the consequences of respiratory muscle weakness in ALS [1]. However, Bourke et al. [2] found no improvement in survival of patients with severe bulbar dysfunction using NIV. In this way, the objectives of this study were to determine the prognostic factors associated with NIV failure in the whole group of ALS patients using NIV and to assess the effect of NIV on survival of ALS patients related to the degree of bulbar dysfunction at NIV initiation.

\section{Materials and methods}

This prospective study, using an intention-to-treat approach, was performed in an ALS referral unit from January 2013 to December 2015 and included those patients diagnosed with definitive or probable ALS, according to the revised El Escorial criteria [8], who were managed at the unit and in whom NIV was initiated. Informed consent was obtained from all the patients who took part in the study and the protocol was approved by the hospital's ethics committee. Exclusion criteria were refusal to participate in the study, the presence of bronchial disease, the presence of concomitant progressive disease with less than a year's life expectancy, the use of NIV for $<4$ consecutive hours at night, ALS with slow disease progression ( $>3$ years) or the presence of severe frontotemporal dementia associated with ALS that had the potential to interfere with procedures.

NIV was indicated in the presence of any of the following criteria [9]: presence of hypoventilation symptoms (dyspnoea, orthopnoea, fatigue, morning headache, daytime hypersomnolence and decreased cognitive function), arterial carbon dioxide tension $\left(\mathrm{PaCO}_{2}\right)>45 \mathrm{mmHg}$, time spent with oxygen saturation measured by pulse oximetry $\left(\mathrm{SpO}_{2}\right)<90 \%$ at night $\left(\%\right.$ sleepS $\left.\mathrm{pO}_{2}<90\right)$ being $>5 \%$ and forced vital capacity $<50 \%$ of predicted.

Demographic, neurological and respiratory function data were collected at the time NIV was indicated. Demographic variables included sex, age, body mass index and ALS onset. Neurological function was evaluated using the Revised Amyotrophic Lateral Sclerosis Rating Scale (ALSFRS-R) [10] and bulbar dysfunction was assessed in accordance with the Norris scale bulbar subscore (NBS) [11]. Respiratory function tests were performed under medically stable conditions. At the time NIV was indicated, spirometry was performed using a pneumotachometer (MS 2000; C. Schatzman, Madrid, Spain) in accordance with the European Respiratory Society guidelines and suggested values [12]. Maximum inspiratory pressure and maximal expiratory pressure were measured (Electrometer 78.905A; Hewlett-Packard, Andover, MA, USA) in accordance with the BLACK and НyatT [13] technique. Respiratory function tests were performed using an oronasal mask (King Mask; King System, Noblesville, IN, USA) for those patients with severe facial weakness due to bulbar impairment, to avoid air leaks from the mouthpiece.

Peak cough flow (PCF), maximum insufflation capacity (MIC), manually (PCFMIC) and mechanically (PCFMI-E) assisted PCF were assessed with a sealed oronasal mask (King Mask; King System, Noblesville, IN, USA) and a pneumotachograph spirometer (MS 2000), as described previously [14].

Night-time cardiorespiratory monitoring (MEC-1000; Shenzhen Mindray Biomedical Electronic Co., Shenzhen, China) during a hospital stay was performed both at NIV indication while breathing 
spontaneously and after NIV adjustments. Data concerning oxygen saturation $\left(\mathrm{SpO}_{2}\right)$, heart rate, respiratory rate, ECG activity and thoracoabdominal movements were graphically and analogically recorded. \% sleep $\mathrm{p}_{2}<90$, minimal nocturnal oxygen saturation $\left(\mathrm{SpO}_{2} \mathrm{~min}\right)$ and mean nocturnal oxygen saturation were also recorded. Arterial blood gas tests were performed on awakening (Radiometer ABL 500; Radiometer, Copenhagen, Denmark) after nocturnal monitoring.

Over the course of the disease and before the need to provide respiratory muscle aids, the team was made aware of the patient's own wishes regarding the management of respiratory problems. All patients who refused NIV were fully informed of their medical situation, the benefits of treatment with NIV and the difficulties of adapting to NIV, and they had the opportunity to put any queries regarding the procedure to the multidisciplinary medical team.

The initial implementation of NIV took place during a standard scheduled in-hospital stay with a portable ventilator in volume-cycled assist-control mode (Vivo 50 (Breas Medical, Mölndal, Sweden) or Trilogy (Philips Respironics, Madrid, Spain)), as described previously [15]. Oronasal (ResMed (Madrid, Spain) or Philips Respironics), lipseal (Tyco-Puritan Bennett, Pleasanton, CA, USA) or nasal (Philips Respironics or Healthdyne (Marietta, GA, USA)) interfaces were used as appropriate to ensure the comfort and effectiveness of NIV and prevent air leaks. NIV was considered to be effective when $\%$ sleep $\mathrm{PpO}_{2}<90$ using NIV was $<5 \%, \mathrm{PaCO}_{2}$ while using NIV was $<45 \mathrm{mmHg}$ and hypoventilation symptoms did not occur [16]. In those subjects in whom symptoms of hypoventilation, hypercapnia or respiratory accessory muscle use persisted during the daytime despite effective nocturnal NIV, daytime NIV was provided via a mouthpiece (Philips Respironics), lipseal mouthpiece (Tyco-Puritan Bennett) or nasal pillow interface (Fisher \& Paykel Healthcare (Irvine, CA, USA) or Air Liquide Healthcare (Bovezzo, Italy)), as appropriate. Continuous NIV was defined as taking place when the ventilator was used for $>20 \mathrm{~h}$ per day [1].

All patients received therapeutic procedures in accordance with expert guidelines [17]. A clinical and functional assessment was scheduled every 3 months. Mechanically assisted coughing (MAC) was prescribed when PCF was $<4.25 \mathrm{~L} \cdot \mathrm{s}^{-1}[14]$.

Patients in whom NIV was indicated were placed in one of two groups. The NIV group was formed of those patients who agreed to NIV treatment. The no-NIV group was formed of those patients who refused treatment with NIV despite receiving full information about the effects of NIV on the natural course of ALS; they refused even to try out NIV. This group was considered to be the control group and they received standard care in accordance with current guidelines [17].

\section{Study end-points}

Survival was taken to be the period from disease onset and NIV indication to tracheostomy or death, if the patient refused a tracheostomy. Tracheostomy was considered to be indicated when NIV could not provide adequate alveolar ventilation or when MAC was unable to remove respiratory secretions. Severe bulbar dysfunction was defined as NBS $\leqslant 12$ and no or moderate bulbar dysfunction was considered when NBS $>12$ [18].

\section{Statistical analysis}

Data are presented as mean \pm SD for continuous, normally distributed variables, and $n$ (\%) for binary and categorical variables. Data comparisons were performed using a paired Student t-test and a Chi-squared test for categorical variables. For variables without a normal distribution, the Mann-Whitney test and Wilcoxon test for paired data were used. Long-term survival was assessed with Kaplan-Meier charts, applying the log-rank test to compare differences in survival between those patients using NIV and those who refused it. A stepwise Cox proportional hazards model was used to study the prognostic factors for survival. The multivariate analysis model was adjusted for causes of death or tracheostomy due to ineffective NIV and included those variables that exhibited a significant association in the univariate model. Receiver operating characteristic (ROC) curves were used to identify a cut-off point in those prognostic variables for the whole group of ALS patients on NIV. Statistical significance was taken as $\mathrm{p}<0.05$.

\section{Results}

During the period of the study, NIV was initiated in 163 ALS patients (figure 1). 23 patients were excluded (two patients with bronchial disease, three patients with frontotemporal dementia associated with ALS and 12 NIV-intolerant patients (NBS 22.14 \pm 9.11 , two with severe bulbar dysfunction), and six patients with slow disease progression. Thus, 140 were enrolled in the study: 120 underwent NIV and 20 refused NIV. Table 1 shows the main data at NIV indication for patients in both groups. Statistical differences were found in NBS, $\mathrm{PaO}_{2}, \mathrm{PaCO}_{2}$ and $\mathrm{S}_{2} \mathrm{O}_{2}$ min at night. At NIV indication, among those patients who accepted NIV, $55(45.8 \%)$ had a percutaneous endoscopic gastrostomy for enteral nutrition and 


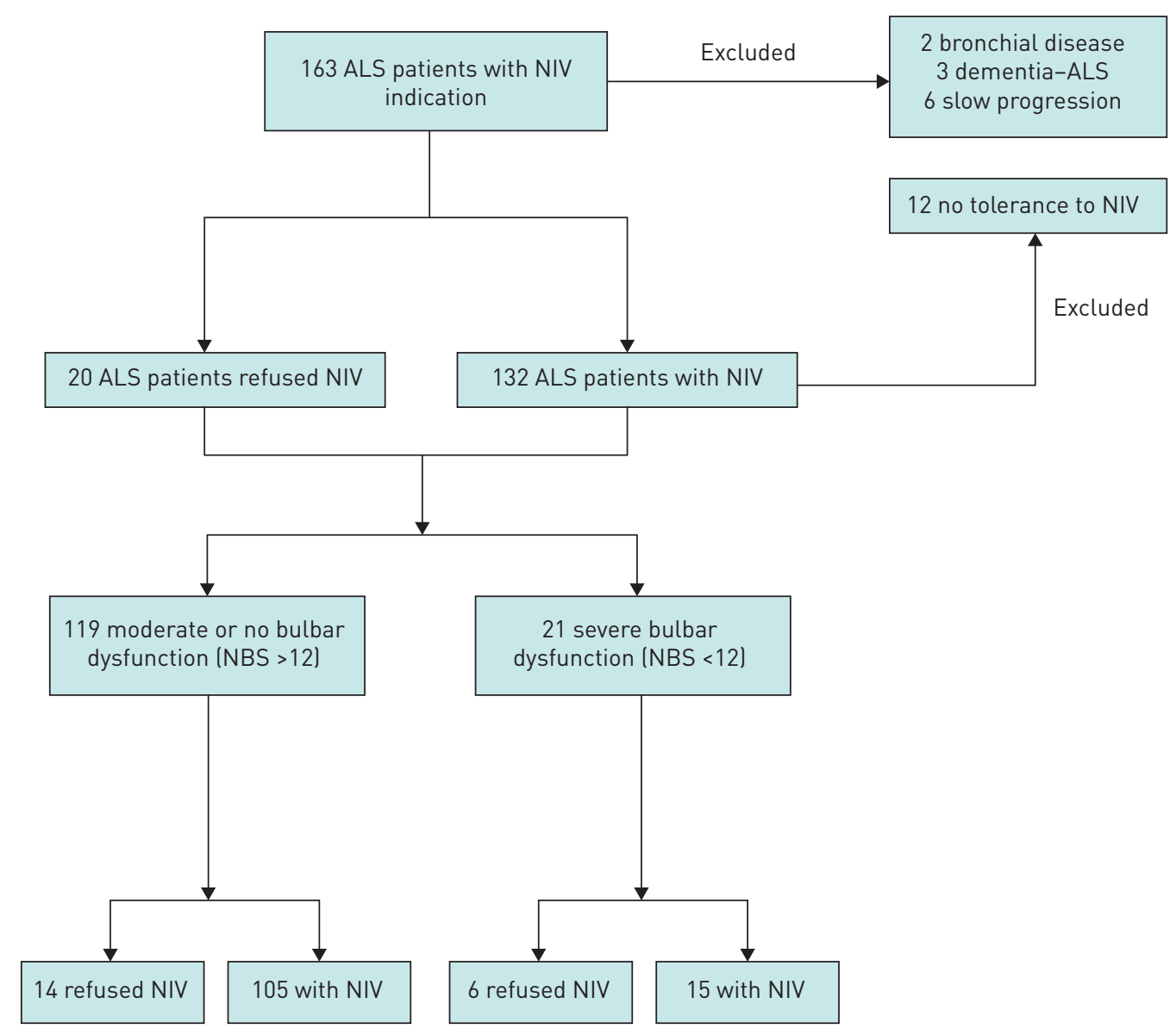

FIGURE 1 Trial profile. ALS: amyotrophic lateral sclerosis; NIV: noninvasive ventilation; NBS: Norris scale bulbar subscore.

92 (76.7\%) were using MAC. Among those who refused NIV, nine (45.0\%) had a gastrostomy and all of them also refused MAC therapy. In the NIV group, 15 patients had severe bulbar dysfunction and six in the no-NIV group had severe bulbar dysfunction.

NIV improved nocturnal oximetry and gas exchange parameters in all patients in the NIV group (table 2). The mean tidal volume used was $782.50 \pm 152.06 \mathrm{~mL}$ and the breathing frequency was $14.53 \pm 1.12$ breaths $\cdot \min ^{-1}$. Among those patients with no or moderate bulbar dysfunction, $90.47 \%$ used oronasal masks at night, $5.71 \%$ lipseals and $3.80 \%$ a nasal mask; all the patients with severe bulbar dysfunction used oronasal masks at night. No patient received supplementary oxygen. No statistical differences were found between those patients with no or moderate bulbar dysfunction and those with severe bulbar impairment with regard to oximetry or gas exchange parameters while using NIV or ventilator parameters (table 3). Over the course of the study, no patient changed ventilator mode.

NIV was able to relieve hypoventilation symptoms in $95(89.49 \%)$ patients with no or moderate bulbar dysfunction and in $14(82.86 \%)$ patients with severe bulbar dysfunction $(\mathrm{p}=0.720)$. At NIV initiation, mean time using NIV was $9.31 \pm 4.47 \mathrm{~h}$. No statistical differences $(\mathrm{p}=0.129)$ in compliance were found between those patients with no or moderate bulbar dysfunction $\left(9.52 \pm 4.67 \mathrm{~h} \cdot \mathrm{day}^{-1}\right)$ and those with severe bulbar impairment $\left(7.66 \pm 1.29 \mathrm{~h} \cdot \mathrm{day}^{-1}\right)$. At the end of the study the mean daily hours of use of NIV were $12.29 \pm 6.42 \mathrm{~h}$.

In the whole of the group of ALS patients, 25 (20.08\%) used continuous NIV at the end of the study, with time spent under continuous NIV being $15.52 \pm 11.17$ months. Only one patient who presented severe bulbar dysfunction at NIV initiation was using continuous NIV at the end of the study; this patient used a lipseal during day and an oronasal mask during night.

Survival in the NIV group was significantly greater than in the no-NIV group (table 4 and figure 2). All patients who rejected NIV died due to respiratory failure. In the NIV group, the main causes of noninvasive management failure were ineffective NIV due to bulbar impairment (49.38\%), failure of 


\begin{tabular}{|c|c|c|c|}
\hline & NIV & No NIV & p-value \\
\hline Patients & 120 & 20 & \\
\hline Age years & $64.05 \pm 9.11$ & $66.05 \pm 10.27$ & 0.373 \\
\hline Males/females & $56 / 64$ & $6 / 14$ & 0.164 \\
\hline Spinal/bulbar ALS onset & $81 / 39$ & $13 / 7$ & 0.826 \\
\hline Time from ALS onset to NIV months & $22.30 \pm 10.51$ & $23.35 \pm 10.27$ & 0.680 \\
\hline $\mathrm{BMI} \mathrm{kg} \cdot \mathrm{m}^{-2}$ & $26.15 \pm 4.23$ & $24.28 \pm 3.56$ & 0.055 \\
\hline ALSFRS-R & $29.01 \pm 7.84$ & $28.94 \pm 7.22$ & 0.973 \\
\hline NBS & $26.75 \pm 10.33$ & $18.84 \pm 8.30$ & 0.001 \\
\hline No or moderate/severe bulbar dysfunction & $105 / 15$ & $14 / 6$ & 0.052 \\
\hline FVC L & $1.45 \pm 0.80$ & $1.24 \pm 1.01$ & 0.387 \\
\hline FVC $\%$ predicted & $49.28 \pm 23.05$ & $44.75 \pm 26.85$ & 0.484 \\
\hline MIC L & $1.96 \pm 0.95$ & $1.58 \pm 1.21$ & 0.240 \\
\hline PCF L.s ${ }^{-1}$ & $3.48 \pm 1.69$ & $2.88 \pm 1.49$ & 0.114 \\
\hline PCFMIC L.S ${ }^{-1}$ & $4.07 \pm 1.94$ & $3.22 \pm 1.88$ & 0.108 \\
\hline PCFMI-E L.s ${ }^{-1}$ & $3.70 \pm 1.07$ & $3.26 \pm 0.64$ & 0.090 \\
\hline$P_{\max } \mathrm{cmH}_{2} \mathrm{O}$ & $-42.37 \pm 22.82$ & $-35.33 \pm 21.90$ & 0.220 \\
\hline$P$ Emax $\mathrm{CmH}_{2} \mathrm{O}$ & $65.54 \pm 42.28$ & $58.72 \pm 40.95$ & 0.519 \\
\hline $\mathrm{PaO}_{2} \mathrm{mmHg}$ & $74.32 \pm 11.95$ & $81.41 \pm 11.34$ & 0.027 \\
\hline $\mathrm{PaCO}_{2} \mathrm{mmHg}$ & $50.34 \pm 8.68$ & $45.52 \pm 7.42$ & 0.023 \\
\hline $\mathrm{HCO}_{3}^{-} \mathrm{mmol} \cdot \mathrm{L}^{-1}$ & $29.02 \pm 3.09$ & $20.70 \pm 3.65$ & 0.740 \\
\hline$\%$ sleep $\mathrm{Sp}_{2}<90$ & $30.96 \pm 28.74 \%$ & $18.94 \pm 31.04 \%$ & 0.162 \\
\hline $\mathrm{SpO}_{2}$ mean & $91.68 \pm 3.03 \%$ & $92.62 \pm 2.84 \%$ & 0.239 \\
\hline $\mathrm{SpO}_{2} \min$ & $79.76 \pm 9.30 \%$ & $86.93 \pm 6.48 \%$ & 0.004 \\
\hline \multicolumn{4}{|c|}{ 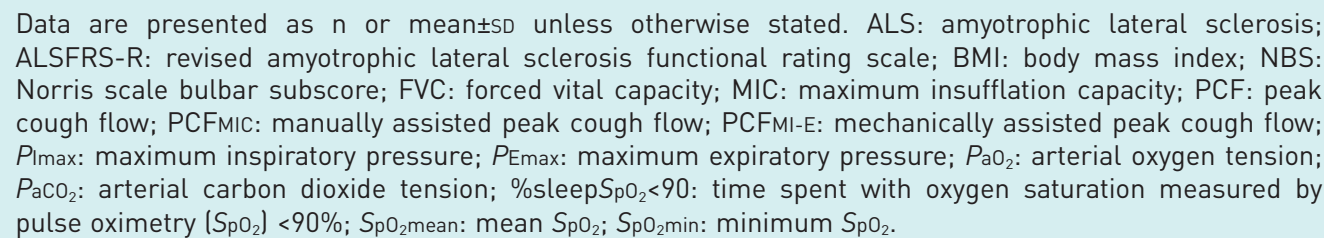 } \\
\hline
\end{tabular}

respiratory secretion management (11.11\%) and sudden death $(9.87 \%)$. With informed consent, a tracheostomy was performed in 25 (30.86\%) patients in whom noninvasive management failed.

When patients were compared in terms of site of ALS onset, all patients who agreed to receive NIV presented longer survival from NIV than those who refused NIV: spinal onset and NIV, median 24.00 months (95\% CI 17.03-30.96 months); spinal onset without NIV, median 2.00 months (95\% CI 0.23-3.76 months) ( $\mathrm{p}=0.001$ ); bulbar onset and NIV, median 12.00 months (95\% CI 9.60 to 14.40 months); bulbar onset without NIV, median 4.00 months (95\%CI 2.04-5.95 months) ( $\mathrm{p}<0.001)$.

With regard to those patients with moderate or no bulbar dysfunction at NIV indication, patients using NIV (NBS 29.30 \pm 8.37 ) presented longer survival than those using standard treatment (NBS 22.36 \pm 6.52 )

TABLE 2 Blood gas and nocturnal gas exchange parameters at baseline situation and while using noninvasive ventilation (NIV) in NIV-group patients

\begin{tabular}{|c|c|c|c|}
\hline & Baseline & Using NIV & p-value \\
\hline $\mathrm{PaO}_{2} \mathrm{mmHg}$ & $74.32 \pm 11.95$ & $84.06 \pm 11.42$ & $<0.001$ \\
\hline $\mathrm{PaCO}_{2} \mathrm{mmHg}$ & $50.34 \pm 8.68$ & $42.11 \pm 4.32$ & $<0.001$ \\
\hline$\%$ sleep $\mathrm{SpO}_{2}<90$ & $30.96 \pm 28.74 \%$ & $1.50 \pm 3.5 \%$ & $<0.001$ \\
\hline $\mathrm{SpO}_{2}$ mean & $91.68 \pm 3.03 \%$ & $95.56 \pm 1.50 \%$ & $<0.001$ \\
\hline $\mathrm{SpO}_{2} \min$ & $79.76 \pm 9.30 \%$ & $92.41 \pm 3.39 \%$ & $<0.001$ \\
\hline \multicolumn{4}{|c|}{$\begin{array}{l}\text { Data are presented as mean } \pm \mathrm{SD} \text { unless otherwise stated. } \mathrm{PaO}_{2} \text { : arterial oxygen tension; } \mathrm{PaCO} \text { : arterial } \\
\text { carbon dioxide tension; \%sleepS } \mathrm{SpO}_{2}<90 \text { : time spent with oxygen saturation measured by pulse oximetry } \\
\left(\mathrm{SpO}_{2}\right)<90 \% ; \mathrm{SpO}_{2} \text { mean: mean } \mathrm{SpO}_{2} ; \mathrm{SpO}_{2} \text { min: minimum } \mathrm{SpO}_{2} \text {. }\end{array}$} \\
\hline
\end{tabular}




\begin{tabular}{|c|c|c|c|}
\hline & No or moderate BD & Severe BD & p-value \\
\hline $\mathrm{PaO}_{2} \mathrm{mmHg}$ & $84.21 \pm 1.00$ & $85.80 \pm 14.50$ & 0.817 \\
\hline $\mathrm{PaCO}_{2} \mathrm{mmHg}$ & $41.87 \pm 4.54$ & $43.13 \pm 2.50$ & 0.287 \\
\hline$\%$ sleepSpO $0_{2}<90$ & $1.26 \pm 3.35 \%$ & $1.40 \pm 2.72 \%$ & 0.855 \\
\hline $\mathrm{SpO}_{2}$ mean & $95.73 \pm 1.46 \%$ & $95.49 \pm 1.05 \%$ & 0.294 \\
\hline $\mathrm{SpO}_{2} \min$ & $92.94 \pm 3.32 \%$ & $91.53 \pm 2.69 \%$ & 0.082 \\
\hline V $\mathrm{mL}$ & $790.09 \pm 154.41$ & $727.14 \pm 124.67$ & 0.102 \\
\hline RR breaths-min ${ }^{-1}$ & $14.50 \pm 1.14$ & $14.80 \pm 1.01$ & 0.306 \\
\hline
\end{tabular}

having refused NIV (table 4 and figure 3). Those with severe bulbar dysfunction at NIV indication (NBS 9.40 \pm 2.89 ) also presented longer survival than those who refused NIV (NBS 9.00 \pm 2.82 ) (table 4 and figure 3).

Table 5 shows the results from the univariate analysis of the prognostic factors for ALS patients using NIV. In the multivariate analysis, adjusted to take ineffective NIV into account, the only variables that were found to be prognostic factors for patients using NIV were NBS (hazard ratio (HR) 0.5, 95\% CI 0.92-0.97; $\mathrm{p}=0.001$ ) and \%sleep $\mathrm{pO}_{2}<90$ while using NIV (HR 1.12, 95\% CI 1.01-1.24; $\mathrm{p}=0.02$ ). Cut-off points could not be calculated because no variable presented a statistically significant area under the curve during the ROC analysis.

\section{Discussion}

The findings of the present study show that volume-cycled NIV and MAC prolong survival not only in ALS patients with no or moderate bulbar dysfunction, but also in some with severe bulbar impairment, demonstrating the usefulness of these procedures if the relevant expertise is available. Moreover, we found that the severity of bulbar dysfunction, measured using NBS at NIV initiation, and the quality of ventilation, as measured by $\%$ sleep $\mathrm{pO}_{2}<90$, are the most important prognostic factors associated with treatment failure for the NIV group as a whole.

The management of respiratory problems in ALS is a critical issue because, as both our previous and current results show, the main cause of death in such patients without respiratory muscle aids is respiratory failure due to respiratory muscle weakness $[15,18]$. NIV has been found to prolong survival in ALS, with a reported median survival from 8 to 18 months from NIV initiation, although the wide range of reported survival rates is striking [2, 7, 19-21]. Previous studies have been conducted to determine prognostic factors of ALS while using NIV. PeYsson et al. [20] found that survival from NIV was independently and inversely correlated with age at diagnosis and the necessity of MAC for mucus removal, although MAC effectiveness was not reported. BERLOWITZ [22], in a retrospective study focusing on survival

\section{TABLE 4 Survival data}

\begin{tabular}{|c|c|c|c|c|c|c|c|c|c|}
\hline & \multicolumn{3}{|c|}{ All patients ${ }^{\#}$} & \multicolumn{3}{|c|}{ No or moderate $B D^{\text {I }}$} & \multicolumn{3}{|c|}{ Severe BD $^{+}$} \\
\hline & NIV & No NIV & p-value & NIV & No NIV & p-value & NIV & No NIV & p-value \\
\hline Patients & 120 & 20 & & 105 & 14 & & 15 & 6 & \\
\hline $\begin{array}{l}\text { Survival from } \\
\text { NIV months }\end{array}$ & $\begin{array}{c}18.50 \\
(12.62-24.38)\end{array}$ & $\begin{array}{c}3.00 \\
(0.82-5.18)\end{array}$ & 0.001 & $\begin{array}{c}20.00 \\
(13.71-26.28)\end{array}$ & $\begin{array}{c}3.00 \\
(0.55-5.44)\end{array}$ & 0.0001 & $\begin{array}{c}13.00 \\
(9.49-16.50)\end{array}$ & $\begin{array}{c}3.00 \\
(0.85-5.14)\end{array}$ & 0.001 \\
\hline
\end{tabular}

Data are presented as mean $(95 \% \mathrm{CI})$ unless otherwise stated. NIV: noninvasive ventilation; BD: bulbar dysfunction; ALS: amyotrophic lateral sclerosis. ${ }^{\#}: n=140 ;{ }^{\text {ๆ }: ~} n=119 ;{ }^{+}: n=21$. 
a)

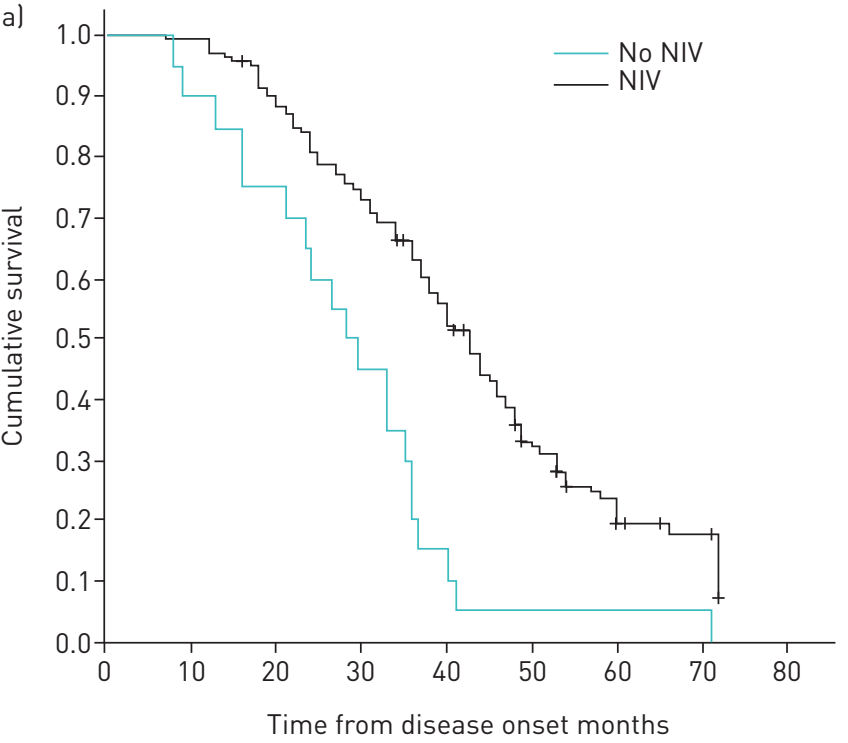

b)

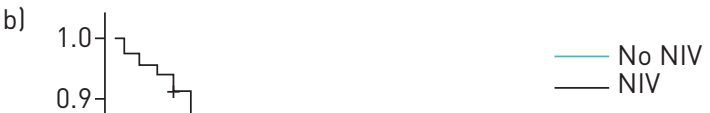

Number at risk

$\begin{array}{lllllllll}\text { No NIV } & 20 & 18 & 15 & 9 & 3 & 1 & 1 & 1\end{array}$

NIV

120

89

$\begin{array}{llll}64 & 33 & 22 & 12\end{array}$

$\begin{array}{lcccccccc}\text { Number } & \text { at risk } & & & & 1 & 1 & 1 & 1 \\ \text { No NIV } & 20 & 5 & 3 & 2 & 1 & 41 & 34 & 31 \\ \text { NIV } & 119 & 109 & 84 & 62 & 54 & 41\end{array}$

FIGURE 2 Survival without tracheostomy a) from disease onset and b) from noninvasive ventilation (NIV) indication. Total population.

from ALS onset, reported a surprising finding in that NIV provided a greater benefit to those ALS patients with bulbar onset; however, the severity of bulbar impairment at NIV indication was not reported and NIV was initiated in the bulbar onset subgroup at an earlier stage. Moreover, time from ALS onset to NIV in the bulbar group was greater in the NIV group than the survival in bulbar group who refused NIV (24.50 versus 13.57 months), showing that the reported advantage of survival in bulbar patients was not related to NIV. In contrast, in our study, no differences were found in patients with severe bulbar dysfunction between the NIV and no-NIV groups in the time from ALS onset to NIV indication (23.03 \pm 11.19 versus $20.25 \pm 11.19$ months, $\mathrm{p}=0.604)$. GonZALEZ-CalZADA et al. [23], also in a retrospective analysis, observed that the two prognostic factors in ALS patients using NIV were the severity of bulbar dysfunction and ALSFRS-R scores at NIV initiation. None of these studies reported the causes of death of the patients using NIV. The results of our study show that ALS patients using NIV may die due to causes that are unrelated to NIV failure (e.g. failure to manage respiratory secretions with MAC), which is consistent with the results of PEYsson et al. [20], and sudden death. Thus, we designed this study in order to determine prognostic factors related to NIV failure. Our results show that the severity of bulbar dysfunction at NIV initiation is a prognostic factor in ALS patients with regard to treatment failure; bulbar impairment has been identified as a prognostic factor for survival in ALS [24]. Another important finding of the present study is that $\%$ sleep $\mathrm{PPO}_{2}<90$ while using NIV is a further prognostic factor in ALS patients using NIV. This is related to the question of achieving effective ventilation in ALS. Recently, it has been found that those ALS patients in whom effective NIV is achieved, with corrected nocturnal desaturations, present greater survival; GonZALEZ-Bermejo et al. [25] found that those ALS patients with ineffective NIV presented significantly higher $\%$ sleep $\mathrm{pO}_{2}<90$ indices at NIV initiation, leading to lower survival in this group of patients. Moreover, the occurrence of obstructive upper airway events in ALS patients using NIV without desaturations has been found to be associated with poor prognoses [26].

Previous studies have found that severe bulbar impairment is one of the most important factors associated with poor NIV tolerance in ALS [7, 15]. Problems associated with bulbar dysfunction include difficulties in secretion management, drooling, choking, aspiration and NIV compliance. Our results show an increase in survival in those patients using volume NIV and MAC, even in those with severe bulbar dysfunction. Bourke et al. [2], in the only randomised controlled trial of NIV in ALS, found that in those patients with severe bulbar impairment, no improvement in survival was produced despite an increase in quality of life. However, certain limitations of Bourke's study could explain these negative results: the trial was not powered for a survival analysis in this group of patients, duration of NIV use in patients with severe bulbar impairment patients was low $\left(3.8 \mathrm{~h} \cdot \mathrm{day}^{-1}\right.$, below the limit at which patients are considered to be NIV tolerant [7]) and MAC was only used towards the end of the randomised controlled trial, once licenced in the UK (secretions were managed throughout with huffing, breath stacking, manually assisted coughing and, when these measures failed, insertion of a minitracheostomy, an invasive procedure) [27]. 

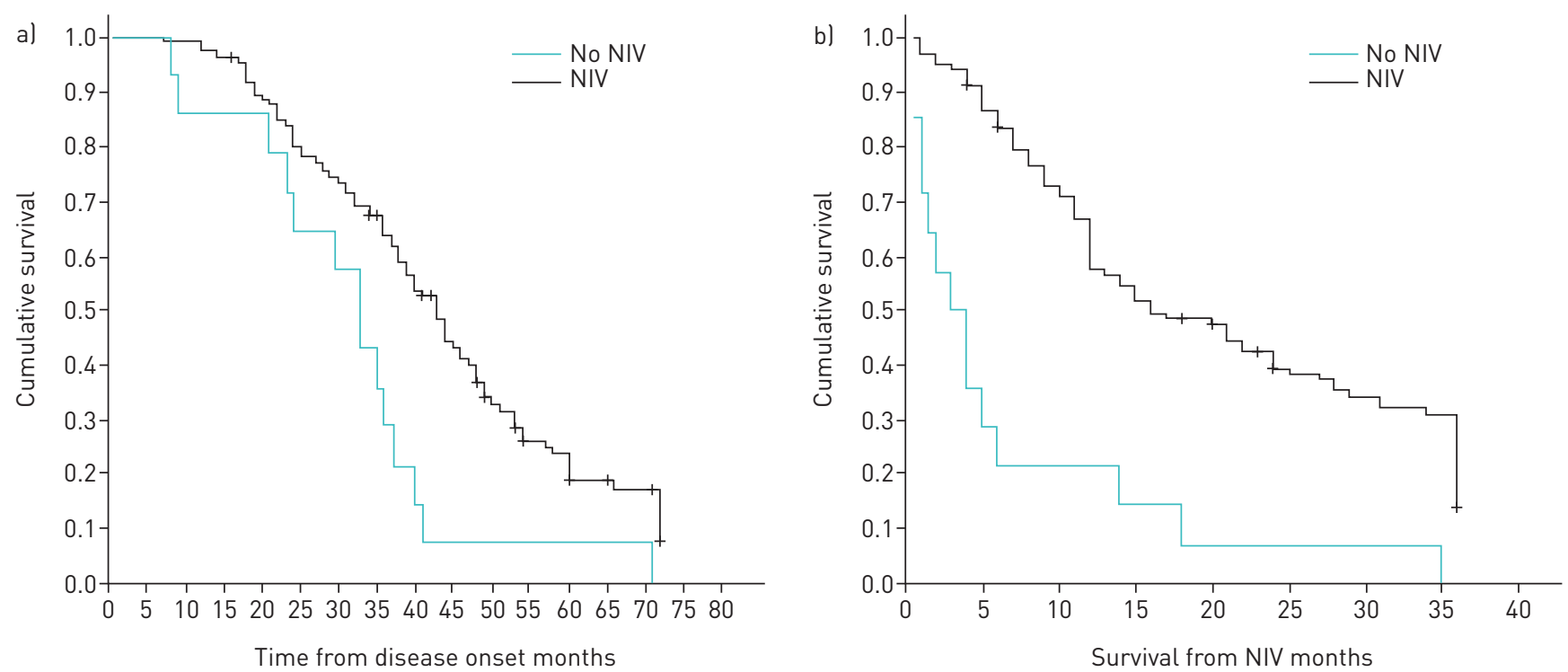

Number at risk

Time from disease onset months

$\begin{array}{llllllllllllllll}\text { No NIV } & 14 & 14 & 12 & 12 & 9 & 8 & 6 & 3 & 3 & 1 & 1 & 1 & 1 & 1 & 1\end{array}$

NIV $\quad 105105104101938377695743 \quad 3122 \quad 201311$

$\begin{array}{lcccccccc}\text { Number at risk } & & & & & & & \\ \text { No NIV } & 14 & 5 & 3 & 2 & 1 & 1 & 1 & 1 \\ \text { NIV } & 105 & 95 & 75 & 56 & 49 & 37 & 32 & 29\end{array}$

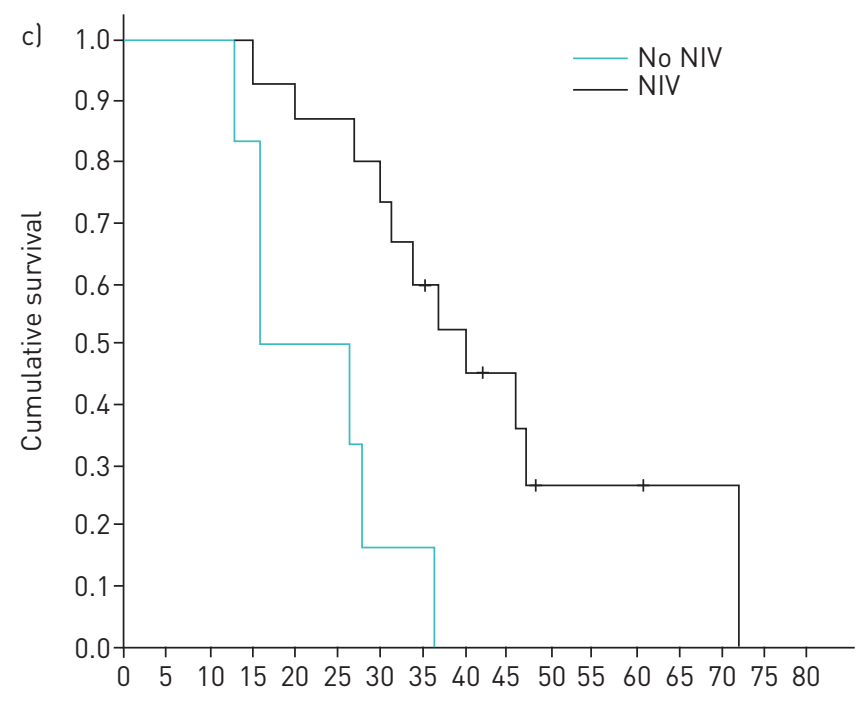

Time from disease onset months

Number at risk

No NIV $\quad \begin{array}{lllllllll}6 & 6 & 6 & 5 & 3 & 3 & 1 & 1\end{array}$

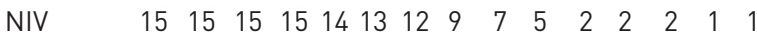

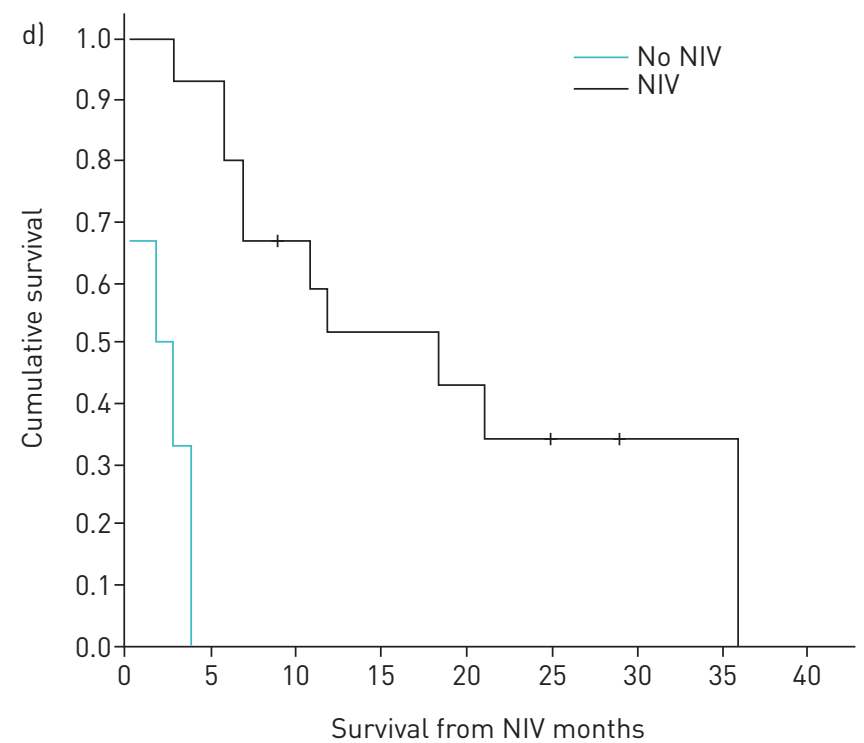

Number at risk

$\begin{array}{lclllllll}\text { No NIV } & 6 & & & & & & & \\ \text { NIV } & 15 & 8 & 6 & 5 & 4 & 3 & 2 & 2\end{array}$

FIGURE 3 Survival without tracheostomy. a) Patients with no or moderate bulbar dysfunction from disease onset. b) Patients with no or moderate bulbar dysfunction from noninvasive ventilation (NIV) indication. c) Patients with severe bulbar dysfunction from disease onset. d) Patients with severe bulbar dysfunction from NIV indication.

In contrast with these figures, all of our patients with severe bulbar impairment were NIV tolerant $\left(7.66 \pm 1.29 \mathrm{~h} \cdot \mathrm{day}^{-1}\right)$ and all patients' respiratory secretions were managed in a uniform way in accordance with current guidelines. However, despite this relationship with NIV tolerance and in contrast with the findings of Bourke's study, ABoussouan et al. [7] found that NIV was able to prolong survival in those patients with severe bulbar dysfunction who were able to tolerate NIV. Our study has found similar results (intolerant patients were excluded), showing the positive effect of NIV on survival of patients with severe bulbar dysfunction who are NIV tolerant. Additionally, the severity of bulbar dysfunction has also been found to be associated with NIV effectiveness both in a medically stable situation and during an acute chest episode $[18,21]$. 


\begin{tabular}{|c|c|c|}
\hline Factor (mean) & $\operatorname{HR}(95 \% \mathrm{CI})$ & p-value \\
\hline Age (64.08 years) & $1.01(0.98-1.03)$ & 0.600 \\
\hline Male sex & $1.43(0.91-2.24)$ & 0.114 \\
\hline Bulbar onset & $2.13(1.35-3.36)$ & 0.001 \\
\hline Time from ALS onset to NIV (22.60 months) & $0.99(0.97-1.01)$ & 0.320 \\
\hline BMI $\left(26.06 \mathrm{~kg} \cdot \mathrm{m}^{-2}\right)$ & $0.95(0.89-1.01)$ & 0.070 \\
\hline FVC $(1.48 \mathrm{~L})$ & $0.51(0.36-0.72)$ & 0.001 \\
\hline FVC $\%$ predicted $(49.33 \%)$ & $0.98(0.97-0.99)$ & 0.001 \\
\hline MIC (1.91 L) & $0.58(0.43-0.78)$ & 0.001 \\
\hline PCF $\left(3.55 L \cdot S^{-1}\right)$ & $0.73(0.62-0.86)$ & 0.001 \\
\hline PCFMIC $\left(4.13 \mathrm{~L} \cdot \mathrm{S}^{-1}\right)$ & $0.77(0.67-0.89)$ & 0.001 \\
\hline PCFMI-E $\left(3.73\right.$ L.s $\left.{ }^{-1}\right)$ & $0.71(0.56-0.90)$ & 0.005 \\
\hline$P_{\max }\left(-44.73 \mathrm{cmH}_{2} \mathrm{O}\right)$ & $1.01(1.00-1.02)$ & 0.018 \\
\hline$P E \max \left(66.37 \mathrm{cmH}_{2} 0\right)$ & $0.99(0.98-1.00)$ & 0.040 \\
\hline ALSFRS-R $(20.01)$ & $0.95(0.92-0.98)$ & 0.002 \\
\hline NBS $(26.67)$ & $0.95(0.93-0.97)$ & 0.001 \\
\hline $\mathrm{PaO}_{2}$ under NIV $(83.13 \mathrm{mmHg})$ & $0.98(0.97-1.01)$ & 0.286 \\
\hline $\mathrm{PaCO}_{2}$ under NIV (42.12 mmHg) & $1.04(0.99-1.09)$ & 0.134 \\
\hline$\%$ sleep $\mathrm{PO}_{2}<90$ under NIV $(1.20 \%)$ & $1.11(1.04-1.19)$ & 0.002 \\
\hline \multicolumn{3}{|c|}{$\begin{array}{l}\text { HR: hazard ratio; ALS: amyotrophic lateral sclerosis; BMI: body mass index; FVC: forced vital capacity; } \\
\text { MIC: maximum insufflation capacity; PCF: peak cough flow; PCFMIC: manually assisted peak cough flow; } \\
\text { PCFMI-E: mechanically assisted peak cough flow; PImax: maximum inspiratory pressure; PEmax: maximum } \\
\text { expiratory pressure; ALSFRS-R: revised amyotrophic lateral sclerosis functional rating scale; NBS: Norris } \\
\text { scale bulbar subscore; } P_{a O_{2}} \text { : arterial oxygen tension; } \mathrm{PaCO}_{2} \text { : arterial carbon dioxide tension; } \% \mathrm{sleepS}_{2}<90 \text { : } \\
\text { time spent with oxygen saturation measured by pulse oximetry }<90 \% \text {. }\end{array}$} \\
\hline
\end{tabular}

We have been unable to establish cut-off points in the prognostic variables found (NBS and $\%$ sleep $\mathrm{PO}_{2}<90$ under NIV). In our view, two reasons for this are: the fact that the progression of ALS, including bulbar dysfunction, is not linear and presents great variability between patients [28]; and the presence of respiratory events during NIV in ALS patients that do not produce desaturations but do lead to a decrease in survival [26].

With regard to the use of NIV in ALS patients, based on current knowledge $[19,21,25,26]$ and the results of the present study, two recommendations for those with severe bulbar dysfunction can be made: great efforts should be undertaken to control the problems associated with bulbar dysfunction that could affect NIV adherence, in order to improve tolerance; and close monitoring should be carried out during NIV adjustment in order to achieve the lowest possible $\%$ sleep $\mathrm{PO}_{2}<90$ index while using NIV and minimise obstructive events related to bulbar dysfunction, in order to achieve effective ventilation and prolong survival.

The present study has several limitations. Unlike that of BOuRKe et al. [2], we have not used randomised study groups. In mitigation, we would argue that there is a great deal of evidence that NIV prolongs survival in ALS patients, and so, in line with the opinions of other prominent NIV researchers [29-31], we consider that it would be unethical not to provide or offer NIV to ALS patients, given that the Spanish National Health System will provide this treatment to all patients that need it and accept it. For this reason, our control group consisted of those patients who refused NIV after we had provided them with information about the prognosis of the disease and the usefulness of treatment with NIV. Both groups, those who refused and those agreed to receive NIV, were managed in the same way and according to international guidelines, with the exception of NIV. It is important to note that $45 \%$ of those who refused NIV had gastrostomy tubes and therefore had adequate nutrition. Another concern is that patients who refused NIV presented greater severity of bulbar dysfunction, as measured by NBS; however, the proportion of patients with moderate and severe bulbar dysfunction was similar in both groups. In order to minimise this bias, we analysed survival according to the degree of bulbar impairment and in both groups (no or moderate bulbar dysfunction and severe bulbar dysfunction), those patients with NIV presented greater survival.

In conclusion, NIV is able to prolong survival in ALS patients, including in some of those with severe bulbar dysfunction at NIV indication. The severity of bulbar dysfunction at NIV initiation and \% sleep $\mathrm{PO}_{2}<90$ while using NIV are the prognostic factors for NIV failure in ALS patients. 
Author Contributions: J. Sancho and E. Servera conceived and designed the study. J. Sancho, D. Martínez, E. Bures, J.L. Díaz and A. Ponz acquired the data. J. Sancho, D. Martínez and E. Servera were analysed and interpreted the data. J. Sancho drafted the first version of the manuscript. J. Sancho and E. Servera redrafted the manuscript with input from all authors. All authors approved the final version of manuscript.

Conflict of interest: E. Bures reports receiving grants from the Institute of Health Research INCLIVA, outside the submitted work.

\section{References}

$1 \quad$ Bach JR. Amyotrophic lateral sclerosis: prolongation of life by non-invasive respiratory aids. Chest 2002; 122: 92-98.

2 Bourke SC, Tomlinson M, Williams TL, et al. Effects of non-invasive ventilation on survival and quality of life in patients with amyotrophic lateral sclerosis: a randomised controlled trial. Lancet Neurol 2006; 5: 140-147.

3 Bedard ME, McKim D. Daytime mouthpiece for continuous noninvasive ventilation in individuals with amyotrophic lateral sclerosis. Respir Care 2017; 62: 387-388.

4 Toussaint M, Steens M, Wasteels G, et al. Diurnal ventilation via mouthpiece: survival in end-stage Duchenne patients. Eur Respir J 2006; 28: 549-555.

5 Bach JR. Amyotrophic lateral sclerosis: predictors for prolongation of life by noninvasive respiratory aids. Arch Phys Med Rehabil 1995; 76: 828-832.

6 Hadjikoutis S, Wiles CM. Respiratory complications related to bulbar dysfunction in motor neuron disease. Acta Neurol Scand 2001; 103: 207-213.

7 Aboussouan LS, Khan SU, Meeker DP, et al. Effect of noninvasive positive-pressure ventilation on survival in amyotrophic lateral sclerosis. Ann Intern Med 1997; 127: 450-453.

8 Brooks RD, Miller RG, Swash M, et al. El Escorial revisited: revised criteria for the diagnosis of amyotrophic lateral sclerosis. Amyotroph Lateral Scler Other Motor Neuron Disord 2000; 1: 293-299.

9 Consensus Conference Report. Clinical indications for noninvasive positive pressure ventilation in chronic respiratory failure due to restrictive lung disease, COPD, and nocturnal hypoventilation. Chest 1999; 116: 521-534.

10 Cedarbaum JM, Stambler N, Malta E, et al. The ALSFRS-R: a revised ALS functional rating scale that incorporates assessments of respiratory function. BDNF ALS Study Group (Phase III). The ALSFRS-R: a revised ALS functional rating scale that incorporates assessments of respiratory function. BDNF ALS Study Group (Phase III). J Neurol Sci 1999; 169: 13-21.

11 Lacomblez L, Bouche P, Bensimon G, et al. A double-blind, placebo-controlled trial of high doses of gangliosides in amyotrophic lateral sclerosis. Neurology 1989; 39: 1635-1637.

12 Quanjer PH, Tammeling GJ, Cotes JE, et al. Lung volumes and forced ventilatory flows: report of working party "Standardization of Lung Function Test." Eur Respir J 1993; 6: Suppl. 16, 5-40.

13 Black LF, Hyatt RE. Maximal respiratory pressures: normal values and relationship to age and sex. Am Rev Respir Dis 1969; 99: 696-702.

14 Sancho J, Servera E, Díaz J, et al. Predictors of ineffective cough during a chest infection in patients with stable amyotrophic lateral sclerosis. Am J Respir Crit Care Med 2007; 175: 1266-1271.

15 Martinez D, Sancho J, Servera E, et al. Tolerance of volume control noninvasive ventilation in subjects with amyotrophic lateral sclerosis. Respir Care 2015; 60: 1765-1771.

16 Janssens JP, Borel JC, Pepin JL. Nocturnal monitoring of home non-invasive ventilation: the contribution of simple tools such as pulse oximetry, capnography, built-in ventilator software and autonomic markers of sleep fragmentation. Thorax 2011; 66: 438-445.

17 Miller RG, Jackson CE, Kasarskis EJ, et al. Practice parameter update: The care of the patient with amyotrophic lateral sclerosis: Drug, nutritional, and respiratory therapies (an evidence-based review): report of the Quality Standards Subcommittee of the American Academy of Neurology. Neurology 2009; 73: 1218-1226.

18 Servera E, Sancho J, Bañuls P, et al. Bulbar impairment score predicts noninvasive volume-cycled ventilation failure during an acute lower respiratory tract infection in ALS. J Neurol Sci 2015; 358: 97-91.

19 Lo Coco D, Marchese S, Pesco MC, et al. Non-invasive positive-pressure ventilation in ALS: predictors of tolerance and survival. Neurology 2006; 6: 761-765.

20 Peysson S, Vanderberghe N, Philit F, et al. Factors predicting survival following noninvasive ventilation in amyotrophic lateral sclerosis. Eur Neurol J 2008; 59: 164-171.

21 Sancho J, Servera E, Morelot-Panzini C, et al. Noninvasive ventilation effectiveness and the effect of ventilatory mode on survival in ALS patients. Amyotroph Lateral Scler Frontotemporal Degener 2014; 15: 55-61.

22 Berlowitz DJ, Howard ME, Fiore JF, et al. Identifyng who will benefit from non-invasive ventilation in amyotrophic lateral sclerosis/motor neuron disease in a clinical cohort. J Neurol Neurosurg Psychiatry 2016; 87: 280-286.

23 Gonzalez-Calzada N, Prats-Soro E, Mateu-Gomez Ll, et al. Factors predicting survival in amyotrophic lateral sclerosis patients on non-invasive ventilation. Amyotroph Lateral Scler Frontotemporal Degener 2016; 17: 337-342.

24 Farrero E, Prats E, Povedano M, et al. Survival in amyotrophic lateral sclerosis with home mechanical ventilation. The impact of Systematic respiratory assessment and bulbar involvement. Chest 2005; 127: 2132-2138.

25 Gonzalez-Bermejo J, Morelot-Pancini C, Arnol N, et al. Prognostic value of efficiently correcting nocturnal desaturations after one month of non-invasive ventilation in amyotrophic lateral sclerosis: a retrospective monocentre observational cohort study. Amyotroph Lateral Scler Frontotemporal Degener 2013; 14: 373-379.

26 George M, Attali V, Golmard JL, et al. reduced survival in patients with ALS with upper airway obstructive events on non-invasive ventilation. J Neurol Neurosurg Psychiatry 2016; 87: 1045-1050.

27 Bourke SC, Tomlinson M, Williams TL, et al. Non-invasive ventilation in amyotrophic lateral sclerosis-Authors' reply. Lancet Neurol 2006; 5: 292-293.

28 Gordon PH, Cheng B, Salachas F, et al. Progression in ALS is not linear but is curvilinear. J Neurol 2010; 257 1713-1717.

29 Hill NS. Nonivasive positive pressure ventilation in neuromuscular disease. Enough is enough! Chest 1994; 105: 337-338.

30 Bach JR, Chiou M. Limitations of evidence-based medicine. Rev Port Pneumol 2006; 22: 4-5.

31 Radunovic A, Annane D, Rafiq MK, et al. Mechanical ventilation for amyotrophic lateral sclerosis/motor neuron disease. Cochrane Database Syst Rev. 2017; 10: CD004427. 